\title{
HUBUNGAN RISIKO JATUH DENGAN TAKUT JATUH PADA LANSIA DI PANTI WERDHA SURABAYA
}

\author{
Anastasia Putu Martha Anggarani ${ }^{1}$, Raditya Kurniawan Djoar $^{2}$ \\ Program Studi Fisioterapi STIKES Katolik St.Vincentius a Paulo Surabaya ${ }^{1}$ \\ Program Studi Keperawatan STIKES Katolik St.Vincentius a Paulo Surabaya ${ }^{2}$ \\ Diterima : 2 Oktober 2018, Disetujui : 9 Oktober 2018
}

\begin{abstract}
Background: Fear of fall will result in reduced equilibrium control and reduced confidence to prevent falls, which will further increase the incidence of falls in the elderly. One effort that can be done to reduce the fear of fall which is the trigger of the incidence of fall is to make preventive efforts that analyze the risk factors, but currently the risk factors associated with fear of falling in the elderly in Indonesia has not been analyzed. The purpose of this study is to analyze the risk relationship falls with the incidence of falling afraid of the elderly living in Panti Werdha Surabaya. Method: The research design was analytic observational with cross sectional approach involving 155 elderly living in Panti Werdha Surabaya. Sampling technique using proportional random sampling method. Existing data were analyzed using Contingency Coefficient Test with significant level of 0.05. Results : The result of the statistical test showed that there was a falling risk relationship with the fear of falling with the correlation value of 0.355 with the significant level of 0.000 ( $p<0.05)$, the positive direction indicated by the value of $B=1.425$. Conclusion: The risk of falling has a very meaningful relationship with the fear of falling elderly at Panti Werdha Surabaya.
\end{abstract}

Keywords: Risk of Falling, Fear of Falling, Elderly

\section{PENDAHULUAN}

Proses penuaan menyebabkan penurunan kemampuan fisik yang mengakibatkan berbagai permasalahan salah satunya adalah kejadian jatuh. Kejadian jatuh tersebut akan menyebabkan penurunan kemandirian lansia dalam melakukan aktivitas fungsionalnya. Jumlah kejadian jatuh pada lansia cukup tinggi, setidaknya 28\%-35\% orang yang berusia 65 tahun mengalami jatuh setiap tahun dan jumlah tersebut meningkat menjadi $32 \%-42 \%$ pada lansia berusia 70 tahun (WHO, 2007). Kejadian jatuh dipengaruhi oleh beberapa faktor, salah satunya adalah faktor personal yaitu takut jatuh. Takut jatuh akan menghambat kualitas hidup lansia dan meningkatkan risiko jatuh melalui pengurangan aktivitas fisik, kepercayaan diri, kekuatan dan keseimbangan. Takut jatuh akan mengakibatkan kontrol keseimbangan berkurang dan pengurangan kepercayaan diri untuk mencegah jatuh, hal tersebut yang akan semakin meningkatkan kejadian jatuh pada lansia (Canada, 2005). Terdapat beberapa faktor yang berhubungan dan menyebabkan takut jatuh salah satunya adalah orang yang memiliki risiko jatuh. Salah satu upaya yang dapat dilakukan untuk mengurangi takut jatuh yang merupakan pemicu kejadian jatuh adalah dengan melakukan upaya preventif yaitu 
menganalisis faktor risiko tersebut, akan tetapi saat ini faktor risiko yang berhubungan dengan takut jatuh pada lansia di Indonesia belum dianalisis.

Kejadian takut jatuh mendapatkan peningkatan perhatian oleh bagian kesehatan masyarakat dalam dua dekade terakhir (Lach, 2005). Menurut penelitian para ahli sekitar 26\%-55\% lansia yang tinggal di masyarakat mengalami takut jatuh, 40\%-73\% lansia yang pernah jatuh ternyata mengalami takut jatuh. Pada lansia, takut jatuh merupakan ketakutan yang terbesar yaitu sekitar 47\% (Howland, 1998) dan kondisi ini lebih banyak terjadi pada perempuan dibandingkan laki-laki. Pada salah satu studi yang dilakukan pada 1000 wanita selama lebih dari 3 tahun, lebih dari sepertiga dari sampel dilaporkan mengalami takut jatuh dan mengalami peningkatan sebanyak $45 \%$ setelah 3 tahun (Lach, 2005). Dalam banyak hal, takut jatuh berpotensi menimbulkan bahaya. Takut jatuh merupakan kekhawatiran jatuh yang berlebihan, hal tersebut mengakibatkan adanya pembatasan gerak saat melakukan aktivitas fungsional. Takut jatuh bisa mengakibatkan pembatasan interaksi sosial dan kecemasan. Dampak adanya peningkatan angka takut jatuh adalah adanya penurunan kemandirian lansia dalam beraktivitas sehari-hari, penurunan kualitas hidup lansia dan penurunan interaksi sosial (Austin, 2007) (L.Murphy, 2002).

Prevalensi takut jatuh akan semakin meningkat sesuai dengan bertambahnya usia (Scheffer, 2007). Penuaan akan menyebabkan terjadinya perubahan fisiologis pada sistem-sistem tubuh antara lain sistem muskuloskeletal, kardiovaskuler, respirasi, saraf, alat indera dan fungsi organ lain (Narinder Kaur
Multani, 2007). Pada saat melakukan aktivitas, individu akan membutuhkan sistem-sistem tersebut salah satunya untuk mempertahankan keseimbangan supaya tidak jatuh. Oleh karena terjadi perubahan fisiologis, lansia akan mengalami penurunan kemampuan untuk mempertahankan keseimbangan saat melakukan aktivitas. Lansia akan memiliki risiko jatuh yang lebih besar. Tujuan penelitihan ini adalah untuk menganalisis hubungan risiko jatuh dengan takut jatuh pada lansia yang tinggal di Panti Werdha Surabaya

\section{METODE PENELITIAN}

Peneliti menggunakan desain penelitian yaitu observasional analitik dengan pendekatan cross sectional. Tempat penelitian ini dilakukan di di panti Wredha di Surabaya di Kecamatan Wonocolo, Genteng, Sambikereb, Rungkut dan Dukuh Pakis di Panti Wredha St.Yosef, Panti Wredha Surya, Panti Wredha Usia Surabaya, Panti Wredha Yayasan Cinta Kasih Ibu Teresa, Panti Wredha Griya Wredha, dan Panti Wredha Anugerah. Sampel pada penelitian ini adalah sebanyak 155 lansia berusia $\geq 60$ tahun, bisa berkomunikasi dengan baik, bisa membaca dan menulis dan yang bersedia menjadi sampel, yang diambil dengan menggunakan teknik Proportional random sampling.

Instrumen dalam penelitihan penelitihan ini terdiri dari kuesioner Modified Falls Efficacy Scale Indonesian Version (Modified FES-I) untuk mengukur takut jatuh dan Timed $U p$ and Go Test (TUG Test) untuk mengukur risiko jatuh. TUG Test valid dan reliabel untuk mengukur keseimbangan saat berjalan (inter rater sebesar 0,94 dan intra rater sebesar 0,95) (Asnandra, 2009). 
Sedangkan uesioner Modified FES-I juga valid dan reliable untuk mengukur takut jatuh pada lansia. Uji validitas dan reabilitas instrumen dalam penelitian ini dilakukan di Panti Werdha Bhakti Luhur, Tropodo dengan jumlah responden 30 lansia. Content validity digunakan dalam uji validitas ini. Hasil koreksi konten kuesioner para ahli dihitung dengan hasil Item content validity $(I-C V I)$ pada rentang $0,857-1$ (nilai valid $>0,78$ ), Sedangkan untuk Sum-Content Validity Index (S-CVI) didapatkan hasil 0,93 (nilai valid > 0,9). Dengan demikian konten kuesioner dinyatakan valid. Reabilitas indeks yang menunjukan sejauh mana kepercayaan, keandalan dan konsisten di suatu alat ukur yang digunakan dalam penelitian, dan harus dilakukan suatu uji. Pengujian ini dilakukan menggunakan aplikasi SPSS versi 16 dengan teknik alpha (cronbach's) dan didapatkan hasil 0,948 sehingga dinyatakan kuesioner ini reliabel untuk digunakan. Uji analisis dalam penelitian ini adalah karakteristik responden disajikan dalam bentuk prosentase. Analisis korelasi menggunakan uji Contingency Coefficient dan menggunakan uji regresi logistik binomial.

\section{HASIL PENELITIAN}

Hasil statistik deskriptif karakteristik responden dapat dilihat pada tabel berikut :
Tabel 1. Karakteristik Responden Penelitian

\begin{tabular}{|c|c|c|}
\hline Variabel & Sub Grup & $\begin{array}{c}\text { Total } \mathbf{n}=155 \\
\text { Mean } \pm \text { SD } / n(\%)\end{array}$ \\
\hline $\begin{array}{l}\text { Usia } \\
\text { (tahun) }\end{array}$ & & $76,3 \pm 8,02$ \\
\hline Jenis & Laki-laki & $46(29,7 \%)$ \\
\hline Kelamin & Perempuan & $109(70,3 \%)$ \\
\hline $\begin{array}{l}\text { Risiko } \\
\text { Jatuh }\end{array}$ & & $22,3 \pm 14,6$ \\
\hline \multirow{6}{*}{ Takut Jatuh } & Ada & $102(65,8 \%)$ \\
\hline & Tidak ada & $53(34,2 \%)$ \\
\hline & & $29,03 \pm 11,3$ \\
\hline & $\begin{array}{l}\text { Kekhawatiran } \\
\text { rendah }\end{array}$ & $43(22,7 \%)$ \\
\hline & $\begin{array}{l}\text { Kekhawatiran } \\
\text { sedang }\end{array}$ & $35(22,6 \%)$ \\
\hline & $\begin{array}{l}\text { Kekhawatiran } \\
\text { tinggi }\end{array}$ & $77(49,7 \%)$ \\
\hline
\end{tabular}

Tabel tersebut menggambarkan rata-rata usia responden 76 tahun berjenis kelamin perempuan $(70,3 \%)$. Sebagian besar responden memiliki rasa takut jatuh $(49,7 \%)$ dan berisiko jatuh $(65,8 \%)$

Tabel 2. Analisis Hubungan Takut Jatuh dengan Risiko Jatuh

\begin{tabular}{ccc}
\hline & \multicolumn{2}{c}{ Takut Jatuh } \\
C & p \\
\hline Risiko Jatuh & 0,355 & $0,000^{\mathrm{b}}$ \\
\hline Tabel 2 menunjukkan bahwa risiko
\end{tabular}
jatuh mempunyai hubungan dengan takut jatuh karena $\mathrm{p}<0,05$ (H0 diterima). Kekuatan hubungan tersebut bersifat sedang karena nilai $\mathrm{C}: 0,25-0,5$ 


\section{PEMBAHASAN}

Keseimbangan merupakan salah satu kunci pokok dalam bergerak (Allison, 2001). Keseimbangan, kekuatan dan fleksibilitas diperlukan untuk mempertahankan postur tubuh yang baik. Ketiga elemen itu merupakan dasar untuk mewujudkan pola jalan yang baik bagi setiap individu. Mekanisme penting pada setiap individu untuk memiliki keseimbangan yang baik melibatkan sistem saraf tepi, propioseptif (rasa posisi sendi), vestibular dan cereberal serta visual (penglihatan) (Felsenthal, 2001) atau dikenal sebagai kontrol postural. Dimana kontrol postural merupakan kemampuan untuk mempertahankan keseimbangan dan orientasi dalam lingkungan gravitasi. Menurut (Chandler, 2000) kontrol postural terdiri dari 3 komponen yaitu sistem sensoris perifer, sistem sentral dan sistem efektor. Ketiga hal tersebut apabila sudah memasuki masa lansia akan mengalami penurunan dalam fungsinya, begitu pula dengan saraf perifer. Central processing berjalan lambat begitu pula pada intepretasi dan informasi sensori sistem dan rekruitmen motor planning, dan respon kehati-hati terhadap lingkungan. Saraf perifer, massa otot skeletal dan kekuatan otot mengalami penurunan fungsi sehingga menyebabkan kontrol postural lebih lambat dan lemah. Penurunan fungsi inilah yang akan menganggu keseimbangan yang pada akhirnya akan menyebabkan risiko jatuh lebih besar (de Villiers, 2015).

Pada penelitian ini didapatkan data $65,8 \%$ responden memiliki risiko jatuh. Hasil analisis korelasi $\mathrm{p}=0,000 \mathrm{r}=0,355$ yang menunjukkan bahwa risiko jatuh mempunyai hubungan dengan kekuatan hubungan bersifat sedang. Uji analisis regresi logistik menunjukkan hasil signifikansi $\mathrm{p}=0,001$ dengan arah positif yang ditunjukkan dengan nilai $\mathrm{B}=1,425$.

Penelitian yang dilakukan Fletcher dan Hiredes menunjukkan adanya hubungan antara risiko jatuh dan takut jatuh (Paula Fletcher, 2004). Kontrol postur, kestabilan gerak volunter dan reaksi mempertahankan keseimbangan saat mendapat gangguan dari luar merupakan dasar untuk mempertahankan keseimbangan. Kontrol postural melibatkan integrasi sistem sensorik, saraf, dan muskuloskeletal, sehingga center of mass tetap dalam base of support dan center of gravity bergerak dengan disertai perubahan base of support sehingga keseimbangan dapat terbentuk (Miyamoto, 2004).

Penelitian lain melaporkan bahwa $78,91 \%$ responden mengalami partial independence saat melakukan transfer, $50,34 \%$ menunjukkan adanya karakter takut jatuh melalui tandem gait test (hasil korelasi $r=0,457$ ) dan $31,39 \%$ mempunyai risiko jatuh (hasil korelasi $\mathrm{r}=-0,44248$ ) (Lopes, 2009). Hal tersebut sejalan dengan penelitian ini bahwa terdapat hubungan antara risiko jatuh dan takut jatuh. Takut jatuh merupakan hasil dari rekruitmen kerja otot agonis dan antagonis saat mempertahankan postur yang buruk, pola jalan yang abnormal, strategi mempertahankan keseimbangan yang buruk, ketergantungan pada alat bantu yang menjamin stabilitas dan peningkatan risiko jatuh pada lansia.

Apabila seseorang sudah merasakan tidak seimbang saat melakukan aktivitas khususnya berjalan, secara langsung akan membuat individu tersebut takut untuk melakukan aktivitas karena perubahan keseimbangannya yang secara sadar bisa menyebabkan jatuh bila dipaksakan untuk beraktivitas. Begitu pula 
pada lansia, perubahan fisik sangat berkaitan erat terhadap risiko jatuh. Selain itu, kondisi medis yang berhubungan dengan gangguan keseimbangan sangat berpengaruh terhadap meningkatnya rasa takut akan jatuh karena orang dengan gangguan keseimbangan sudah kehilangan kepercayaan diri untuk menumpu dengan kaki terutama saat berjalan sehingga memperbesar risiko jatuh (Kumar, 2008). Oleh karena itu perlu diindentifikasi faktor utama penyebab risiko jatuh tersebut sehingga bisa diberikan intervensi yang tepat untuk memperbaiki keseimbangan lansia.

Untuk menentukan intervensi yang tepat, maka diperlukan pemeriksaan yang terdiri dari pemeriksaan pola jalan, keseimbangan dan fungsi sendi pada ekstremitas bawah. Salah satu intervensi yang dapat memperbaiki keseimbangan dan meminimalkan risiko jatuh adalah senam tai chi. Hal tersebut ditunjukkan dalam penelitian yang dilakukan Sattin et al bahwa terdapat peningkatan keseimbangan saat melakukan aktivitas. Tai Chi merupakan olahraga yang didalamnya mengandung gerakan lambat, ritmis, banyak melibatkan gerakan trunk, pemindahan berat badan, koordinasi, dan penyempitan tumpuan. Senam ini dilakukan dilakukan selama 60-90 menit selama 2 sesi per minggu (Sattin, 2005).

\section{KESIMPULAN DAN SARAN}

Kesimpulan dari penelitian ini adalah risiko jatuh memiliki hubungan yang sangat bermakna dengan takut jatuh pada lansia di Panti Werdha Surabaya

Masih banyak faktor risiko yang menyebabkan takut jatuh sehingga perlu dilakukan penelitian lebih lanjut tentang faktor risiko takut jatuh. Untuk menentukan intervensi yang tepat, maka diperlukan pemeriksaan yang terdiri dari pemeriksaan pola jalan, keseimbangan dan fungsi sendi pada ekstremitas bawah. Salah satu intervensi yang dapat memperbaiki keseimbangan dan meminimalkan risiko jatuh adalah senam tai chi. Hal tersebut ditunjukkan dalam penelitian yang dilakukan Sattin et al bahwa terdapat peningkatan keseimbangan saat melakukan aktivitas. Tai Chi merupakan olahraga yang didalamnya mengandung gerakan lambat, ritmis, banyak melibatkan gerakan trunk, pemindahan berat badan, koordinasi, dan penyempitan tumpuan. Senam ini dilakukan dilakukan selama 60-90 menit selama 2 sesi per minggu

\section{DAFTAR RUJUKAN}

Alice Scheffer, M. S. (2008). Fear of falling: measurement strategy,prevalence, risk factors and consequences, among older persons. Age and Ageing , 19-24.

Allison, F. (2001). Balance And Vestibular Disorder, Neurogical Rehabilitation. 4th ed. Mosby.

Austin, N. (2007). Fear of Falling in Older Women: A Longitudinal Study of Incidence, Persistence, and Predictors. Journal of the American Geriatrics Society, 1598-1603.

Canada, D. o. (2005). Report on Seniors' falls in Canada. Ontario: Minister of Public Works and Government Services Canada.

Chandler. (2000). Balance And Falls In The Elderly: Issues In Evaluation And Treatment, Geriatric Physical Therapy, Edisi Ke-2. Mosby.

de Villiers, K. (2015). An Approach to Balance Problems and Falls in 
Elderly Persons. South African Medical Journa , 695.

Felsenthal. (2001). Principles Of Geriatric Rehabilitation, Physical Medicine And Rehabilitation. Philadelphia: WB Saunders Company.

Howland. (1998). Covariates of Fear of Falling and Associated Activity Curtailment. Gerontologist, 38.

Jette, A. (2012). Fear of Falling in Older Persons. Netherlands: Springer.

Jung, D. (2008). Fear of Falling in Older Adults:Comprehensive Review. Asian Nursing Research , 214222.

Kumar, S. (2008). Relationship Between Fear of Falling, Balance Impairment and Functional Mobility in Community Dwelling Elderly. IJPMR , 48-52.

L.Murphy, S. (2002). Characteristics Associated with Fear of Falling and Activity Restriction in Community-Living Older Persons. J Am Geriatr Soc .

Lach, H. (2005). Incidence and Risk Factors for Developing Fear of Falling in Older Adults. Public Health Nursing , 45-52.

Lopes, C. S. (2009). Prevalence of fear of falling among a population of older adults and its correlation with mobility, dynamic balance, risk and history of falls. Revista Brasileira de Fisioterapia , 223229.

Miyamoto. (2004). Brazilian Version of the Berg Balance Scale. Brazilian Journal of Medical and Biological Research , 1411-1421.

Narinder Kaur Multani, S. K. (2007). Principles of Geriatric Physiotherapy. New Delhi:
Jaypee Brothers Medical Publishers.

Narjes Nick, I. J. (2013). Educational Intervention for Reducing the Fear of Falling and Improving Balance in the Elderly:A Single Blind Randomized Controlled Trial. International Journal of Community Based Nursing and Midwifery , 208-216.

Paula Fletcher, J. H. (2004). Restriction in Activity Associated with Fear of Falling among Community-Based Seniors Using Home Care Services. Age and Ageing , 273279.

Salked, G. (2000). Quality of Life Related to Fear of Falling and Hip Fracture in Older Women: A Time Trade off Study. British Medical Journal, 341-346.

Sattin, R. W. (2005). Reduction in Fear of Falling Through Intense Tai Chi Exercise Training in Older, Transitionally Frail Adults. American Geriatrics Society, $1168-1178$.

Scheffer. (2007). Fear of Falling: Measurement Strategy, Prevalence, Risk Factors and Consequences among Older Persons. Age and Ageing , 19-24.

WHO. (2007). WHO Global Report on Falls Prevention in Older Age WHO Global Report on Falls Prevention in Older Age. Perancis: WHO. 